\title{
Publisher's Note: Precise measurement of parity violation in polarized muon decay [Phys. Rev. D 84, 032005 (2011)]
}

J.F. Bueno, R. Bayes, Yu. I. Davydov, P. Depommier, W. Faszer, C. A. Gagliardi, A. Gaponenko, D. R. Gill, A. Grossheim, P. Gumplinger, M. D. Hasinoff, R. S. Henderson, A. Hillairet, J. Hu, D. D. Koetke, R. P. MacDonald, G. M. Marshall, E. L. Mathie, R. E. Mischke, K. Olchanski, A. Olin, R. Openshaw, J.-M. Poutissou, R. Poutissou, V. Selivanov, G. Sheffer, B. Shin, T. D. S. Stanislaus, R. Tacik, and R. E. Tribble (Received 21 February 2012; published 28 February 2012)

DOI: 10.1103/PhysRevD.85.039908

PACS numbers: 13.35.Bv, 12.60.Cn, 14.60.Ef, 99.10.Fg

This paper was published online on 9 August 2011 with a typographical error in Eq. (18). Equation (18) should read as " $P_{\mu}^{\pi} \xi=1.00084 \pm 0.00029$ (stat) ${ }_{-0.00063}^{+0.00165}$ (syst)." The equation has been corrected as of 22 February 2012 . The equation is incorrect in the printed version of the journal.

Published by the American Physical Society under the terms of the Creative Commons Attribution 3.0 License. Further distribution of this work must maintain attribution to the author(s) and the published article's title, journal citation, and DOI. 